\title{
Nutritional Quality of Organic Foods
}

\section{Jemima Beryl Mohankumar*}

Emeritus Professor of Nutrition and Dietetics, PSG College of Arts and Science, Coimbatore, TN, India

*Corresponding Author: Jemima Beryl Mohankumar, Emeritus Professor of Nutrition and Dietetics, PSG College of Arts and Science, Coimbatore, TN, India.

Received: August 27, 2019; Published: September 06, 2019

Organic farming can contribute to sustainable food security by improving nutrition intake, supporting livelihoods in rural areas and enhancing biodiversity while simultaneously reducing vulnerability to climate change.

Several published research work on the nutrient composition of organic foods report higher amounts of micronutrients like iron, magnesium, phosphorus, and vitamin $\mathrm{C}$ and less nitrates compared to conventional crops. The minerals that were identified were of greater nutritional significance. Heavy metals that are detrimental to health were found in lower amounts Also it has been reported that the protein content was lower, but of better quality. However, there are several research groups all over the world working on food composition to document the diversity of food and nutrients. Both agricultural techniques and soil type and nutrients have a major impact on food composition. The National Institute of Nutrition, ICMR, has released a new set of data on foods of Indian origin in their Food Composition Tables in 2017. Regional foods and there are consequently analysed by local groups to provide additional data on organic foods.

\section{Antioxidants}

Organic crops such as minor millets, fruits and vegetables like guava, papaya, goose berries, plantains, tomatoes, pumpkin, drumsticks, brinjal and greens which are home grown or kitchen garden have significantly higher concentrations of nutritionally desirable antioxidants compared with their conventionally produced counterparts. These include phenolic acids (19\% higher), flavanones (69\% higher) stilbenes (28\% higher), flavones (26\% higher), flavonols (50\% higher) and anthocyanines (51\% higher) [1].
Smith-Spangler., et al. [2] found no significant difference between organic and conventional products in terms of carotenoids and other non defense-related secondary metabolites such as anthocyanins and tocopherols. The content of plant protection antioxidants like polyphenols depends on the genetic factors (crop variety) and environmental factors. Carotenoids are pigments that have an antioxidant action and act in association with tocopherols to protect the plant from damaging UV radiation. There plant foods grown in tropical regions have higher levels of certain carotenoids. For example ripe and papaya particularly rich in lycopene. Cultivation method is thus of secondary importance as a factor influencing levels of these compounds. On the one hand, the production of organic foods focuses strongly on promoting availability of ripe, local and seasonal produce. While on the other the organic business and trade is being promoted by government agencies to boost income.

\section{Influences on health}

There are many influences on people's health - genetic makeup, environmental pollutants, and lifestyle factors such as smoking, not exercising enough, alcohol consumption, side effects of medicinal and recreational drugs, emotional well-being and more. But diet is increasingly being viewed as playing a key role. However no single dietary habit, including consuming organically grown food, can claim to guarantee good health.

Dairy cattle raised on feeds based primarily on roughage, enhances levels of beneficial fatty acids in milk. These finding have documented that organic milk contained significantly higher levels of omega-3 fatty acids and Vaccenic acid. Vaccenic acid has been shown to attenuate complications observed in the metabolic syn- 
drome, including dyslipidemia, fatty liver disease, and low-grade inflammation [3]. Since milk is also a very good source of nutrients like protein and amino acids, B-complex vitamins and calcium, quality of diets can be enhanced by such foods.

To accord clinical relevance of such claims requires long term studies. It is not possible to witching from conventional to organic foods in the short-term is unlikely to produce clinically relevant effects. Moreover, there are intervention studies exploring food supplementation, and specifically supplementation with vitamin $\mathrm{C}$, carotene and other vitamins, which have demonstrated no effect or even a risk to the subjects [1].

\section{Bibliography}

1. Brandt K., et al. "Agro ecosystem management and nutritional quality of plant foods: the case of organic fruits and vegetables". Critical Reviews in Plant Sciences 30 (2011): 177-197.

2. Smith-Spangler C., et al. "Are organic foods safer or healthier than conventional alternatives?: A systematic review". Annals of Internal Medicine 157 (2012): 348-366.

3. Jacome-Sosa M M., et al. "Diets enriched in trans-11 Vaccenic acid alleviate ectopic lipid accumulation in a rat model of NAFLD and metabolic syndrome". Journal of Nutritional Biochemistry 25 (2014): 692-701.

\section{Volume 3 Issue 10 October 2019}

(C) All rights are reserved by Jemima Beryl Mohankumar. 